\title{
AN EXAMINATION OF CONDITIONS THAT MODERATE NEGATIVE EFFECTS OF SPONSORSHIP TERMINATIONS ON FAN ATTITUDES TOWARD THE FORMER SPONSOR
}

\author{
Reinhard Grohs, University of Innsbruck, Austria \\ Kim Kopfer, WPP GmbH, Austria \\ David M. Woisetschläger, Technische Universität Braunschweig, Germany
}

\begin{abstract}
The sponsorship literature devotes considerable attention to the early stages of a sponsorship relationship and the effects of sponsorship on consumers' awareness of and attitude toward sponsors (Cornwell 2008). Relatively little research has studied the impact on fan behaviour caused by a termination of a sponsorship relationship (Ruth and Strizhakova 2012). While a sponsorship termination might result out of reasonable causes for the sponsor, it usually has an unfavourable impact on fans' attitudes toward the sponsor, particularly when the termination is perceived as unjustified. This paper draws on personal relationship theory to identify conditions that influence negative effects of sponsor initiated sponsorship terminations on perceptions of the (former) sponsor brand.
\end{abstract}

In the context of team sports, fans perceive a strong connection to a team and experience the team's failings and achievements as their own personal success and failure (Ashforth and Mael 1989, Gwinner and Swanson 2003). This situation describes a very close relationship between fan and team, so close that intermediate boundaries between fan and team vanish and an impression of one perceived unity develops. Sponsors intend to "capture a consumer's share of the heart" and become interlinked with a part of the "consumer's extended self" (Madrigal 2000, pp.14, 23). Personal as well as sponsorship relationships develop over time through significant interactions between the relationship partners based on the principle of mutuality and goodwill. Unfortunately, not all relationships endure forever and they fall victim to termination, often following a degenerative episode (Westberg, Stavros and Wilson 2011). In the context of sponsorship, Olkkonen and Tuominen (2006) as well as Farrelly (2010) examine relationship-related causes of sponsorship terminations induced by the sponsor. Recent empirical studies show that sponsorship exit can have unfavourable effects on the sponsor's brand image, depending on corporate (financial) situation (Papies, Knubben and Schnittka 2010), trust in the sponsor's arguments legitimating the decision (Messner and Reinhard 2012) or perceived sponsor motives (Woisetschläger, Grohs and Reisinger 2011). Personal relationship theory suggests specific relationship quality factors that influence the perceived negativity after a break up in human relationships. We expect that this negative effect is stronger if fans perceive a high fit between the sponsor and the sponsored team, if sponsor dependency is high, i.e. the current sponsor is very important or no replacement sponsor is available, and if the team performs poorly. In addition, sponsorship duration is expected to interact with the drivers of negative fan attitude, in that a sponsorship termination after a long time is considered worst in conditions of a good sponsorteam fit with no replacement sponsor at hand.

An experiment was conducted to test the theoretically derived propositions in the context of a soccer team and a fictitious sponsor brand. Data collection took place using an online questionnaire which was posted on the official fan website of the sponsored soccer club and distributed via the official fan club newsletter. A total of 612 respondents participated in the data collection. 483 respondents identified themselves as avid fans of the sponsored club.

The hypotheses were tested using independent samples $t$-tests and ANCOVAs. The study shows that fan attitudes toward a sponsor that terminates a sponsorship of their favourite team are worse than attitudes toward a sponsor that continues the sponsorship. More negative attitudes toward the former sponsor result if the sponsor fits well with the team and if no replacement sponsor is available. Results also indicate marginally more negative attitudes if the sponsor is important and if the team is performing poorly. Overall, sponsors need to worry most if a long-term sponsorship is terminated when no replacement sponsor is available and fans perceive a good match between the team and the (former) sponsor. When a sponsorship does not fulfil organizational expectations, the sponsorship is not renewed or even cancelled. Such sponsor withdrawals are important because sponsors have to deal with potential problems following the termination of a sponsorship deal. In line with personal relationship theory the present experimental study revealed a general negative effect of sponsorship termination on fan attitudes toward a former team sponsor which is further amplified by various relationship quality factors. Despite the advantages of such an experiment in a controlled environment, further research is needed to establish external validity of the findings in the context of real-world sponsorships with real sponsors.

References available upon request. 